\title{
CNC Programming Software Design to Optimizing Batik Stamping Time
}

\section{Rancang Bangun Software Penyusunan Program CNC untuk Optimasi Waktu Pengecapan Batik}

\author{
Rian Prasetyo ${ }^{1}$, Ainur Komariah ${ }^{2}$ \\ ${ }^{1,2}$ Program Studi Teknik Industri, \\ Universitas Veteran Bangun Nusantara, Jalan Letjen Sujono Humardani No 1 Jombor, Sukoharjo, 57521 \\ email : rnprasetyo286@gmail.com \\ doi: https://doi.org/10.31315/opsi.v14i1.4700
}

Received: 23 ${ }^{\text {rd }}$ April 2021; Revised: $5^{\text {th }}$ May 2021; Accepted: $7^{\text {th }}$ May 2021;

Available online: $24^{\text {th }}$ June 2021; Published regularly: June 2021

\begin{abstract}
Batik is an original Indonesian heritage, that must be preserved and it is the mainstay for implementation of "Making Indonesia 4.0”. It was published many research about stamp batik manufacturing, but still have limitation of motive variation and slackly design process. This research aim to develop the way to making CNC program to be quickly, besides of high variation of batik motive. Source code in python programming language, was built for extension tool in inscape software. Extension is used to create stamp point, depend on various motive size. Source code created in .py and inx format will be save in "ekstensi" folder. Based on coordinate point of stamping in stamp batik, CNC program will be created, using "G-code tools" extension that was available in inscape software menubar. CNC programming used extension was built is measured about time of process and compared to manual CNC programming. CNC program that has been built then tested in CAMotics software. The results of this research show that CNC program could maked with this extension for various dimension of batik stamp and in 2, 4, 6, 8, 10, and 12 meters of cloth length. CNC programming with extension developed, can reduce time up to $96.05 \%$.
\end{abstract}

Keywords: Stamp batik; Stamp batik CNC; Stamp batik manufacturing; CNC program

\begin{abstract}
ABSTRAK
Batik merupakan warisan Indonesia yang harus senantiasa dijaga kelestariannya dan merupakan salah satu andalan dalam implementasi Making Indonesia 4.0. Implementasi tersebut telah banyak melahirkan penelitian manufaktur batik cap, tetapi masih terkendala pada kurangnya aplikasi variasi motif dan belum memiliki proses desain yang cepat. Penelitian ini bertujuan untuk mengembangkan cara pembuatan program CNC yang cepat dan dapat mengakomodir variasi motif batik cap. Tahapan penelitian yang dilakukan adalah pembuatan source code ekstensi pada software Inkscape dengan Bahasa pemrograman Python, untuk membuat titik koordinat pengecapan batik cap sesuai dengan variasi ukuran motif, lalu file disimpan dengan format .py dan .inx, dan ditambahkan pada folder ekstensi software Inkscape. Berdasarkan titik koordinat tersebut, nantinya akan dibuat program CNC dengan ekstensi G-code tools yang telah tersedia pada software Inkscape. Pembuatan program CNC dengan ekstensi tersebut selanjutnya diukur waktu prosesnya dan dibandingkan dengan pembuatan program CNC secara manual. Program CNC yang telah dibuat selanjutnya diujicoba dengan software CAMotics yang merupakan simulator CNC. Hasil dari penelitian menunjukkan program CNC dapat dibuat dengan ekstensi yang dikembangkan untuk berbagai ukuran cap batik dan ukuran Panjang kain 2, 4, 6, 8, 10, dan 12 meter. Penggunaan ekstensi pada software inkscape ini dapat mengurangi waktu sampai 96,05\% untuk pembuatan program CNC.
\end{abstract}

Kata Kunci: Batik cap; CNC Batik cap; Manufaktur Batik Cap; Program CNC 


\section{PENDAHULUAN}

Kerajinan batik merupakan budaya asli yang telah menjadi ciri khas dari Indonesia. Sesuai dengan pengakuan dari UNESCO (United Nations Educational Scientific and Cultural Organization) sejak Oktober 2009 (Purba et al., 2020), bahwa batik Indonesia merupakan warisan budaya tidak berwujud (Representative List of Intangible Cultural Heritage). Oleh karena itu penting untuk kita dalam menjaga warisan budaya tersebut agar tidak punah.

Secara teknis batik dihasilkan dari proses pewarnaan kain dengan terdapat malam (wax) sebagai penghalang masuknya warna pada beberapa bagian, sehingga akan menghasilkan kain dengan corak tertentu (Fasla, 2013). Salah satu jenis batik yang ada di Indonesia adalah batik cap. Jenis batik ini menerapkan penggunaan canting cap dari tembaga, sebagai alat untuk menempelkan malam pada kain (Alamsyah, 2018). Bentuk motif batik akan menyesuaikan dengan bentuk motif pada cap tersebut.

Implementasi Making Indonesia 4.0, menjadikan industri batik sebagai salah satu andalan untuk mendukung ketercapaiannya (Setyaningsih, 2020). Produk batik juga memiliki sumbangan yang cukup signifikan pada sektor ekspor pakaian jadi dengan nilai ekspor per tahun 2018, mencapai 734 miliar rupiah (Eskani et al., 2019). Adanya era revolusi industri 4.0 ini tentunya diharapkan dapat membuat produksi batik indonesia dapat berbasis teknologi yang canggih, sehingga dapat cepat memenuhi permintaan pasar.

Produksi batik yang berbasis teknologi sebelumnya telah dilakukan oleh beberapa peneliti, khususnya pada produksi batik cap (Hanif et al., 2017), (Dwinugroho, 2017), (Wibisono et al., 2012). Secara umum pengembangan proses produksi batik cap tersebut menggunakan sistem pengendali komputer $(C N C)$. Akan tetapi belum memiliki alat penyusunan program $C N C$ sendiri, sehingga penyusunan program komputernya masih secara manual. Hal tersebut akan membuat waktu proses penyusunan program $C N C$ menjadi lama dan kurang optimal dari segi waktu produksi, apabila digunakan untuk pengecapan motif batik yang baru dengan dimensi cap yang berbeda. Pengoptimalan waktu tersebut juga sangat dibutuhkan agar time to customers pada produk batik bisa tercapai lebih cepat.

Alat untuk membuat program $C N C$ secara otomatis sebelumnya juga pernah dibuat oleh (Dita, 2017). Alat yang dibuat berupa software desain batik yang dapat memiliki output program $C N C$. Akan tetapi program output dari software ini hanya terbatas pada jenis baju ukuran "M" saja, dan hanya mampu membuat desain sebanyak 8 motif yang tersedia pada software tersebut, sehingga variasi motif akan terbatas dan kurang sesuai dengan kebutuhan konsumen. Hal tersebut terkait dengan penelitian yang dilakukan Asmal et al., (2015), bahwa tuntutan konsumen yang menginginkan variasi desain motif yang beraneka ragam sebanyak $72,8 \%$ berbanding $27,2 \%$ dengan yang tidak setuju. Hal tersebut menunjukkan software yang telah dikembangkan terlalu terbatas pada jenis motif batik tertentu, dan belum bisa mengakomodir kebutuhan konsumen yang menginginkan variasi yang lebih beragam pada motif batik.

Berdasarkan uraian diatas, maka peneliti melakukan pengembangan proses manufaktur batik cap. Pengembangan yang dilakukan adalah pada bagian persiapan pengecapan dengan menggunakan mesin $C N C$ batik cap, yaitu proses pembuatan program $C N C$, untuk mengoptimalkan waktu pembuatannya. Hal tersebut dikarenakan proses pembuatannya saat ini masih manual, dan memerlukan waktu yang lama serta belum mengakomodir berbagai variasi motif batik yang ada.

\section{METODE}

Metode dalam penelitian ini adalah melakukan rancang bangun ekstensi pada software inkscape untuk proses pembuatan program $C N C$. Untuk dihasilkan program $C N C$ tersebut, dilakukan beberapa tahap, antara lain:

\subsection{Pembuatan Source Code Ekstensi}

Pembuatan source code ekstensi merupakan inti dari penelitian ini. Source code akan dibuat dengan bahasa pemrograman python dan diketik menggunakan software notepad ++ . Bahasa pemrograman tersebut dipilih karena compatible dengan file untuk membuat ekstensi pada software inkscape dan cukup banyak digunakan untuk pemrograman komputer.

Penyusunan source code akan memanfaatkan model matematis sebuah gambar yang dimasukkan pada software inkscape. 
Gambar yang dimasukkan ini nantinya akan berupa penampang cap pada batik cap dengan bentuk persegi atau persegi panjang sesuai dengan cap yang akan digunakan untuk produksi batik cap dan gambar titik yang merupakan acuan untuk pengecapan. Dari gambar tersebut, akan diambil titik tengah yang merupakan titik koordinat pengecapan dan akan dilakukan looping seluas ukuran kain batik menggunakan source code yang akan dibuat. Jumlah looping ini akan menyesuaikan ukuran cap yang dimasukkan ke software inkscape, serta dapat memiliki pilihan Panjang kain 2, 4, 6, 8, 10, dan 12 meter. Titik koordinat yang telah ada selanjutnya akan dibuat program $C N C$ menggunakan ekstensi $G$-code tool yang telah ada pada software Inkscape.

Pembuatan source code dalam penelitian ini dibagi menjadi tiga file. Dua file dengan format .py dan satu file dengan format inx. File dengan format .py salah satunya digunakan untuk sourcode model matematis gambar, dan yang lainnya adalah source code proses pembuatan titik koordinat. Satu file dengan format inx merupakan source code untuk interface pada software Inkscape. Penggunaan ketiga file ini saling berintegrasi, sehingga menghasilkan ekstensi yang sesuai dengan kebutuhan.

\subsection{Input Ekstensi pada Software Inkscape}

File yang telah dibuat dimasukkan kedalam folder ekstensi software inkscape. Secara otomatis ketika file sudah ditambahkan, ekstensi pada interface software inkscape akan bertambah. Setelah itu dilakukan running pada ekstensi yang telah ditambahkan dan dilihat terdapat error atau tidak. Apabila masih terdapat error, maka dilakukan editing pada source code. Apabila sudah bisa membuat titik koordinat pengecapan, maka titik-titik tersebut dijadikan acuan dan dilakukan pembuatan program $C N C$ untuk pengecapan batik cap.

\subsection{Ujicoba Ekstensi dan Pembuatan Program CNC}

Setelah didapatkan ekstensi pengecapan batik tersebut, dilakukan pembuatan titik-titik acuan pengecapan pada software inkscape. Titik-titik tersebut memiliki jarak sesuai dengan panjang dan lebar cap berdasarkan data input. Titik-titik pengecapan tersebut juga dapat menyesuaikan panjang kain yang dipilih.
Titik-titik yang telah dibuat pada interface software inkscape, selanjutnya dibuat program CNC menggunakan ekstensi "gcodetools". Pembuatan program $C N C$ dilakukan untuk seluruh pilihan panjang kain yang disediakan. Selain itu juga dilakukan pembuatan program CNC secara manual sebagai pembanding. Masing-masing rangkaian proses pembuatan program $C N C$ tersebut, selanjutnya dihitung waktu prosesnya, lalu dibandingkan.

Program $C N C$ yang telah dibuat juga dilakukan validasi produksi menggunakan software simulasi CNC. Simulasi dilakukan dengan software CAMotics. Hasil simulasi selanjutnya diamati secara visual terkait alur pergerakan tools. Berdasarkan simulasi tersebut akan terlihat, program $C N C$ yang dibuat, sesuai atau tidak dengan proses pengecapan batik dengan menggunakan mesin $C N C$.

\section{HASIL DAN PEMBAHASAN}

Rancang bangun ekstensi dalam penelitian ini mencakup beberapa tahap. Hal ini karena ekstensi tersebut tersusun dari beberapa file yang saling terintegrasi satu dengan yang lainnya. Tahapan tersebut antara lain:

\subsection{Penyusunan Source code}

Pembuatan Source Code dilakukan dengan menggunakan bahasa pemrograman Python untuk didapatkan ekstensi pada software inkscape. Cara kerja ekstensi ini adalah membuat titik-titik pengecapan sesuai dengan ukuran penampang cap dan ukuran kain yang diinputkan. Source code yang dibuat terdiri dari tiga buah file, yaitu, untuk membentuk interface, untuk penyimpanan model matematis, dan untuk mengerjakan perintah sesuai inputan pada software inkscape.

\subsubsection{Interface}

Source code dari interface yang dibuat berdasarkan ekstensi yang sebelumnya telah ada pada software inkscape tersebut. Source code dari interface yang dibuat berisi pilihan ukuran kain,yang akan digunakan untuk pengecapan. Pilihan ukuran kain yang disediakan adalah, 2, 4, 6, 8,10, dan 12 meter. Source code dari interface ini dapat dilihat pada Gambar 1.

Gambar 1 menunjukkan terdapat dua item value utama dari source code tersebut. Dapat dilihat, untuk item value pertama (ukuran1, ukuran2, dst), merupakan data inputan yang akan diolah selanjutnya oleh ekstensi yang 
dibuat dalam penelitian ini. Item value kedua (2 meter, 4 meter, dst) merupakan ukuran yang ditampilkan pada interface, yang nantinya akan dipilih langsung oleh user dari ekstensi ini. Hasil pembuatan source code tersebut selanjutnya disimpan dengan format inx dan diintegrasikan dengan file yang berisi source code proses kerja ekstensi.

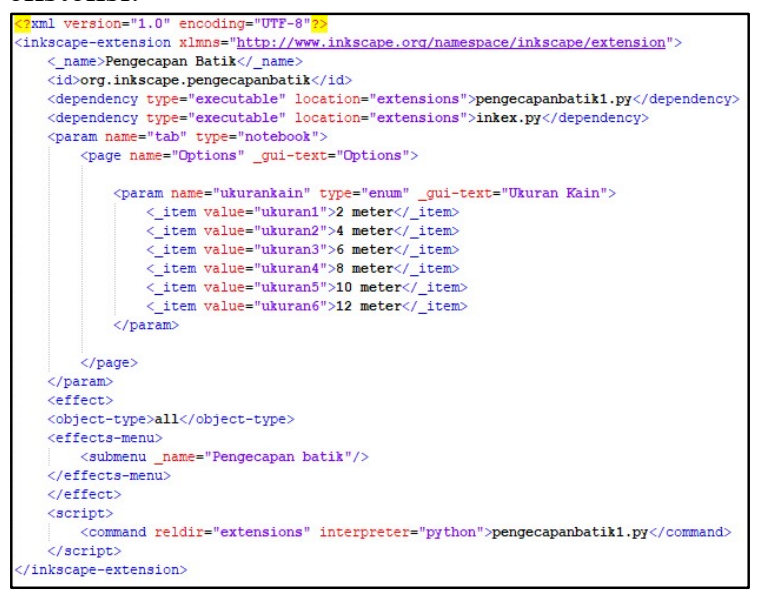

Gambar 1. Source code interface ekstensi yang dibuat pada penelitian ini

\subsubsection{Model Matematis}

Model matematis yang dibuat berdasarkan data gambar yang diambil pada software inkscape yang telah dibuat sebelumnya. Untuk mendapatkan model matematis sebuah gambar pada software Inkscape, dilakukan dengan cara, klik gambar, lalu tekan "ctrl+k" pada keyboard, lalu data model matematis dapat diambil pada XML editor software inkscape tersebut, seperti yang terlihat pada Gambar 2.

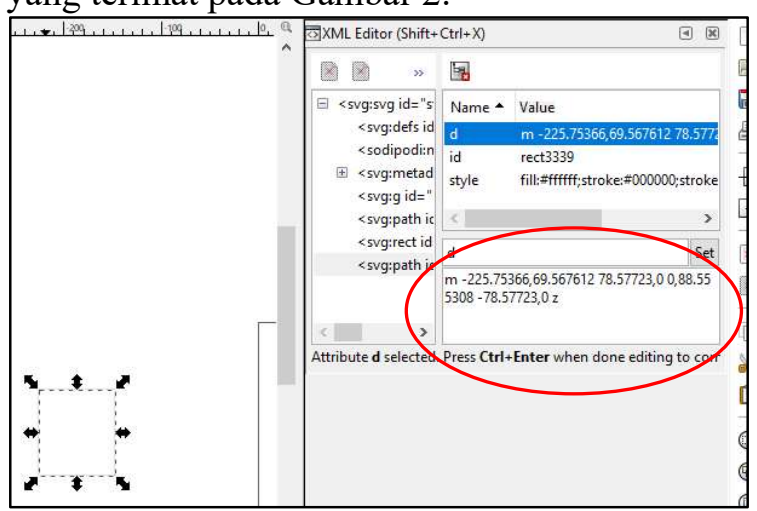

Gambar 2. Model matematis sebuah gambar pada software inkscape

Gambar 2 menunjukkan model matematis (yang ditandai lingkaran merah), pada sebuah gambar persegi. Model matematis pada gambar tersebut terdiri dari beberapa koordinat. Titik koordinat $-225.75366,69.567612$ merupakan titik koordinat awal dari bentuk persegi tersebut.
Koordinat $78.57723,0 ; 0,88.555308$ dan 78.57723,0 merupakan titik luar bentuk persegi secara berurutan. Pada penelitian ini terdapat beberapa model matematis yang digunakan, seperti yang terdapat pada Tabel 1 .

Tabel 1. Model matematis yang digunakan pada penelitian ini

\begin{tabular}{ll}
\hline \multicolumn{1}{c}{ Model Matematis } & \multicolumn{2}{c}{ Kegunaan } \\
\hline $\mathrm{d}=\mathrm{\prime}^{\prime} 0,0{ }^{\prime}$ & $\begin{array}{l}\text { Untuk membuat titik } \\
\text { acuan cap pada } \\
\text { software inkscape }\end{array}$ \\
\hline $\mathrm{d}=' \mathrm{~m}-100,10064,0$ & Untuk membuat \\
$0,64-64,0 \mathrm{z}$ & $\begin{array}{l}\text { penampang ukuran } \\
\text { cap pada software } \\
\end{array}$ \\
\end{tabular}

\subsubsection{Proses Kerja Ekstensi}

File ketiga yang dibuat adalah source code yang berisi proses kerja dari ekstensi tersebut. File ini terdiri dari tiga macam proses kerja ekstensi, berdasarkan logika proses kerja software inkscape. Source code tersebut terbagi menjadi tiga bagian, yaitu, cara penggambaran, fungsi pengenalan nilai berdasarkan input dari interface, dan fungsi untuk memberikan output berdasarkan value yang dipilih.

\section{a. Source code cara penggambaran}

Source code ini berisi yang mencakup cara penggambaran pada software inkscape. Source code tersebut dapat dilihat pada Gambar 3.

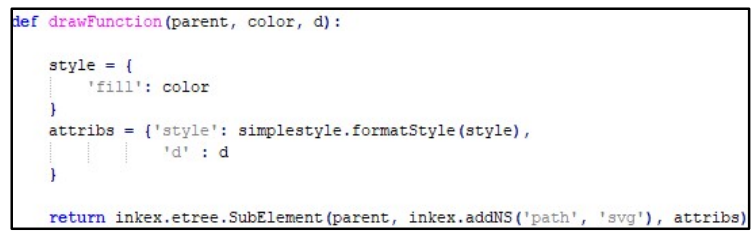

Gambar 3. Source code cara penggambaran pada software inkscape

Gambar 3 menunjukkan baris program proses gambar dengan software inkscape. Cara penggambaran tersebut terdiri dari "parent", "color", dan "d". "Parent" merupakan halaman utama dari software inkscape, yang akan digunakan untuk proses gambar. "color" merupakan warna gambar yang akan dibuat. "d" merupakan model matematis dari gambar tersebut, yang telah dibuat sebelumnya.

b. Fungsi pengenalan nilai input

Source code pada bagian ini terdiri dari sebuah fungsi untuk mengenali data input oleh 
Gambar 4. Source code fungsi pengenalan data

user. Fungsi ini digunakan untuk mengenalkan tipe data agar dapat diproses sesuai dengan perintah yang diberikan pada source code tersebut. Source code fungsi tersebut dapat dilihat pada Gambar 4.

Gambar 4 menunjukkan pengenalan data berdasarkan value input dari interface. Value input dari interface ini dikenalkan sebagai tipe data string. Data tersebut berdasarkan ukuran kain yang terdapat pada interface dari ekstensi yang dibuat dalam penelitian ini. Value input tersebut yang nanti akan diproses untuk penentuan output dari ekstensi yang dibuat tersebut.

\section{c. Fungsi pemberian output}

Source code pada bagian ini terdiri dari baris program untuk memproses pilihan yang telah dimasukkan oleh user. Baris program tersebut dikelompokkan menjadi dua bagian, yaitu baris program untuk mengambil data input ukuran cap oleh user, dan baris program untuk looping proses pengecapan.

Baris program untuk mengambil data input ukuran cap menggunakan data model matematis bentuk persegi berdasarkan input oleh user. Bentuk persegi tersebut merupakan penampang cap batik pada interface software inkscape. Untuk menentukan ukuran penampang tersebut, user hanya perlu mengubah ukuran bentuk persegi pada interface software. Hasil persegi yang telah diubah, selanjutnya dipilah oleh program komputer pada data model matematisnya, untuk didapatkan ukurannya. Data ukuran yang digunakan untuk proses selanjutnya adalah, panjang dan lebar persegi. Panjang dan lebar persegi tersebut selanjutnya digunakan untuk menghitung beberapa data, antara lain, titik awal pengecapan, jarak antar titik pengecapan, jumlah pengecapan sesuai panjang kain, berdasarkan panjang persegi, dan jumlah pengecapan sesuai lebar kain berdasarkan lebar persegi. Untuk baris program pengambilan data input dan proses perhitungan lanjutan dapat dilihat pada Gambar 5.

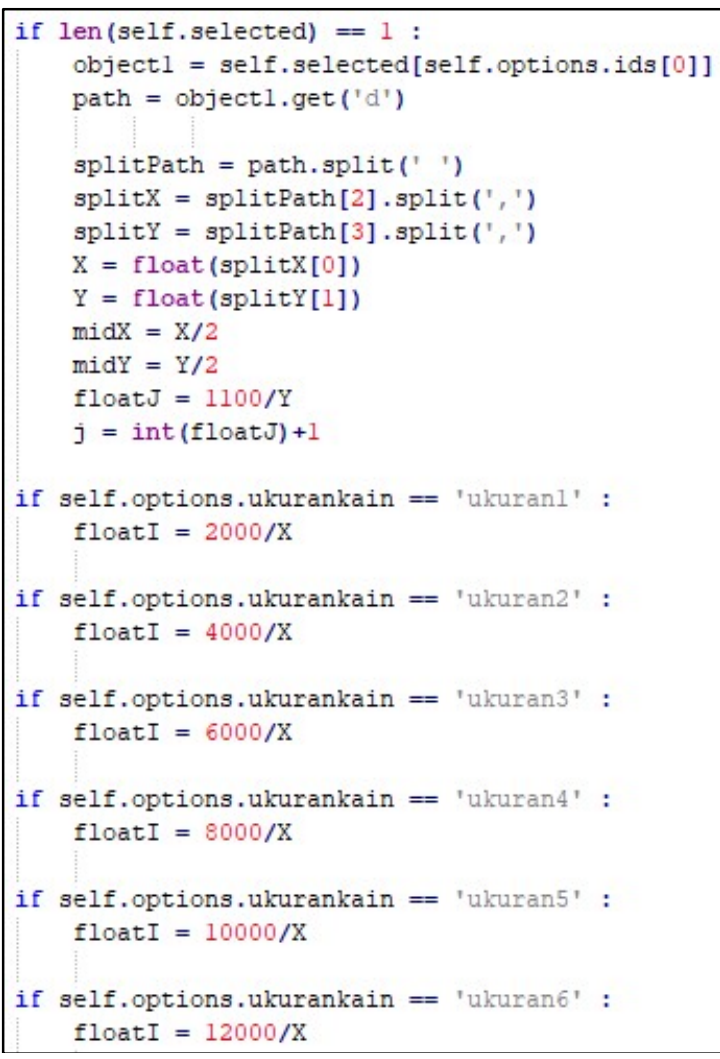

Gambar 5. Baris program pengambilan data input dan proses perhitungan lanjutan

Baris program untuk looping proses pengecapan digunakan untuk membentuk titiktitik pengecapan pada interface software inkscape. Untuk membentuk titik-titik pengecapan tersebut menggunakan baris program dengan perintah "while" looping. Titiktitik tersebut merupakan fungsi penggambaran yang telah dituliskan pada baris program sebelumnya. Titik-titik gambar yang dilakukan proses looping tersebut sejumlah baris dan kolom maksimum berdasarkan panjang dan lebar cap yang telah diinputkan. Titik-titik tersebut yang selanjutnya dijadikan acuan pembuatan program $C N C$ menggunakan ekstensi "gcodetools" yang terdapat pada software inkscape. Baris program looping proses pengecapan dapat dilihat pada Gamba 6 . 


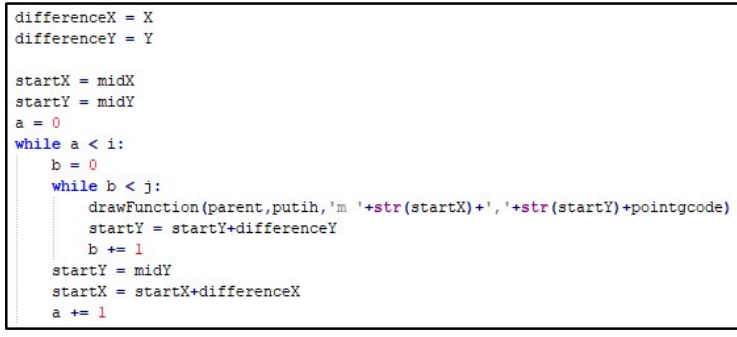

Gambar 6. Baris program looping proses pengecapan

\subsection{Ujicoba ekstensi}

Setelah pembuatan source code selesai selanjutnya ketiga file yang telah dibuat, dimasukkan ke dalam folder ekstensi pada instalasi software inkscape. Ketiga file tersebut harus terletak dalam satu folder. Hal ini agar ketiga file tersebut bisa saling terintegrasi.

Setelah file dimasukkan, lalu ekstensi tersebut dibuka pada software inkscape. Untuk membukanya bisa dilakukan dengan cara klik "extensions", lalu pilih ekstensi pengecapan batik yang telah dibuat. setelah ekstensi dibuka akan mundul interface, seperti yang terlihat pada Gambar 7. Setelah ekstensi dibuka, pilih ukuran kain lalu klik "apply". Setelah itu akan muncul gambar persegi yang merupakan penampang bentuk cap. Setelah itu, klik pada persegi, dan ubah ukuran panjang dan lebar persegi sesuai ukuran cap yang diinginkan pada lingkaran merah yang terlihat pada Gambar 8. Setelah itu tekan "apply" lagi untuk penggambaran titiktitik pengecapan.

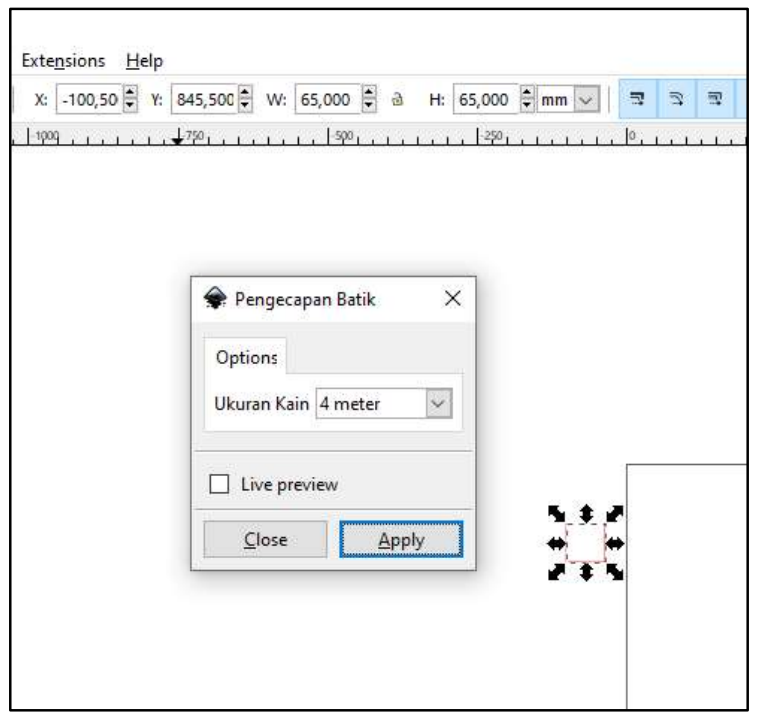

Gambar 8. Input ukuran cap sesuai kebutuhan

Setelah proses penggambaran, titik-titik tersebut tidak akan terlihat, namun bisa dideteksi dengan menekan $\mathrm{Ctrl}+\mathrm{A}$ pada keyboard. Titik- titik pengecapan yang dibuat untuk panjang kain 4 meter dan ukuran cap 200 × $200 \mathrm{~mm}$, dapat dilihat pada Gambar 9. Titik-titik pada gambar tersebut, sejumlah 126, dengan jumlah titik pengecapan sebanyak 21 titik untuk sejajar sumbu $x$ dan 6 titik sejajar sumbu y. Hal ini menunjukkan jumlah titik pengecapan tersebut sudah memenuhi luas area kain, yaitu $4000 \mathrm{x}$ $1100 \mathrm{~mm}$.

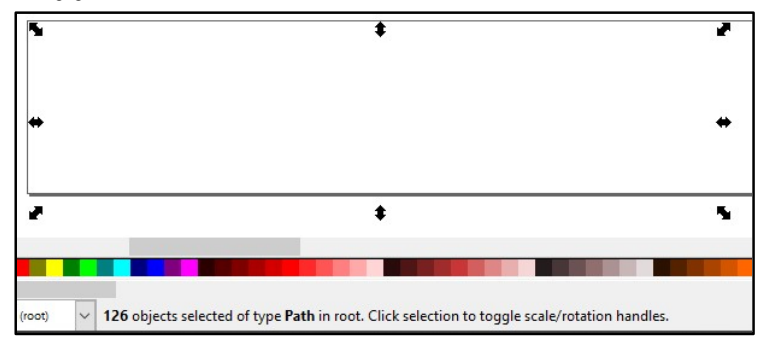

Gambar 9. Titik-titik pengecapan untuk panjang kain 4 meter

\subsection{Ujicoba Pembuatan Program $\mathrm{CNC}$}

Program CNC dalam penelitian ini ditujukan untuk pengecapan malam batik dengan mesin $C N C$. Program $C N C$ dibuat setelah penggambaran titik pengecapan telah dilakukan dengan ekstensi "Pengecapan Batik" yang telah dibiat dalam penelitian ini. Program CNC dibuat menggunakan software inkscape dengan ekstensi "gcodetools". Ekstensi tersebut secara default telah ada pada inkscape.

Untuk pembuatan program $C N C$ terlebih dahulu ditentukan titik orientasi menggunakan perintah "Orientation Point" yangterdapat pada ekstensi "gcodetools". Cara penentuannya setelah membuka perintah tersebut, selanjutnya dipilih "3-points mode" agar dapat menentukan 3 titik koordinat awal. Titik orientasi yang telah dibuat, selanjutnya dilakukan editing untuk mendapatkan titik koordinat orientasi 0,$0 ; 0,100$, dan 100,0, seperti yang terlihat pada Gambar 10 .

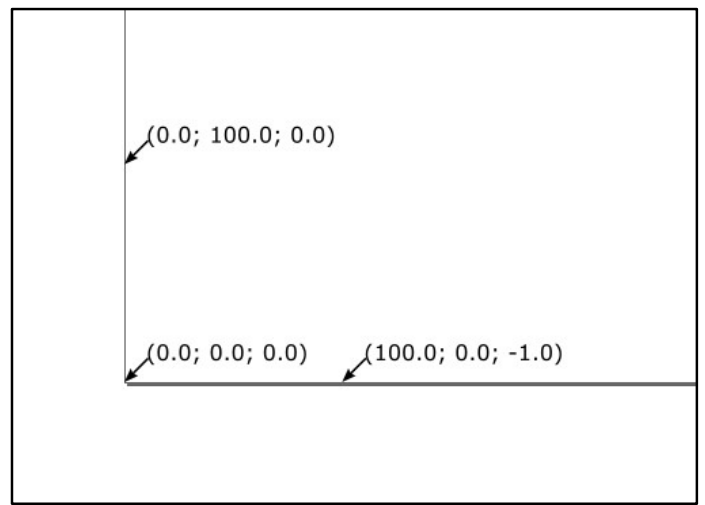

Gambar 10. Titik koordinat orientasi 
Setelah didapatkan titik koordinat orientasi, selanjutnya dilakukan pembuatan program $C N C$ menggunakan perintah "Path to Gcode" pada ekstensi "gcodetools". Setelah interface "Path to gcode" terbuka pilih cutting order menjadi "subpath by subpath", seperti yang terlihat pada Gambar 11. Setelah itu klik "apply" dan ditunggu sampai proses pembuatan program $C N C$ selesai. Setelah program $C N C$ dibuat, file dengan format $n g c$ dapat dibuka pada folder penyimpanan.

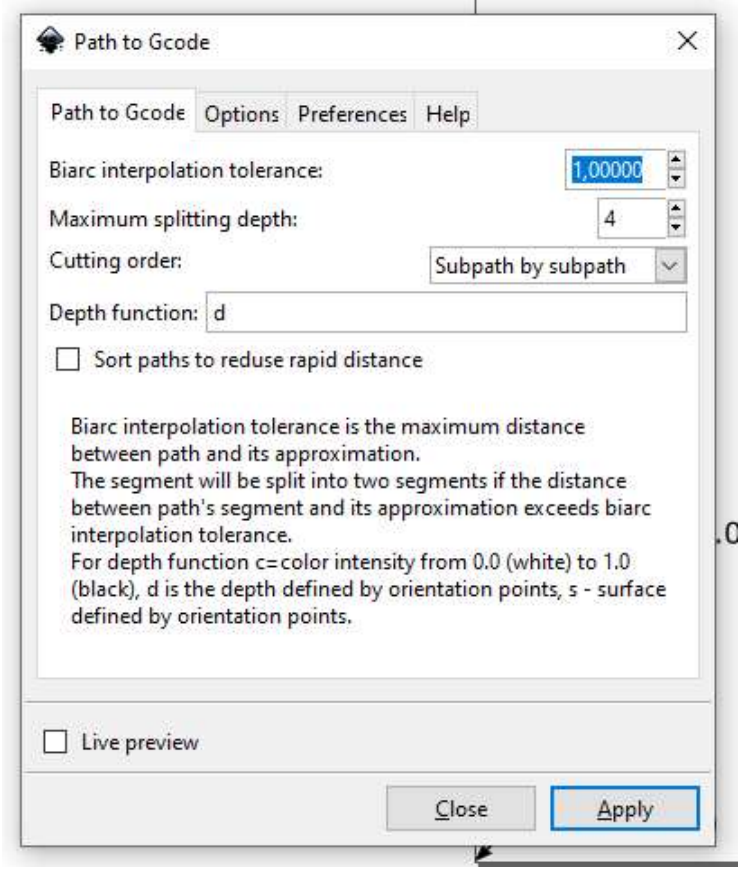

Gambar 11. Interface Path to Gcode

\subsection{Validasi Hasil Ujicoba}

Berdasarkan program $C N C$ yang telah dibuat menggunakan ekstensi yang dikembangkan, perlu dilihat apakah program $C N C$ tersebut bisa dioperasikan atau tidak. Program $C N C$ yang dicoba dengan simulator adalah untuk panjang kain 2 meter. Untuk pengoperasiannya digunakan $C N C$ simulator. Software yang digunakan sebagai simulator ini adalah CAMotics. Untuk menggunakan simulator tersebut, file program $C N C$ dimasukkan, lalu simulator dijalankan. Hasil ujicoba dengan simulator ini menghasilkan alur pergerakan tools $C N C$ berdasarkan garis kontur warna merah untuk pergerakan berdasarkan sumbu $\mathrm{x}$ dan $\mathrm{y}$, serta garis warna hijau untuk pergerakan berdasarkan sumbu $\mathrm{z}$, yang dapat dilihat pada Gambar 12.

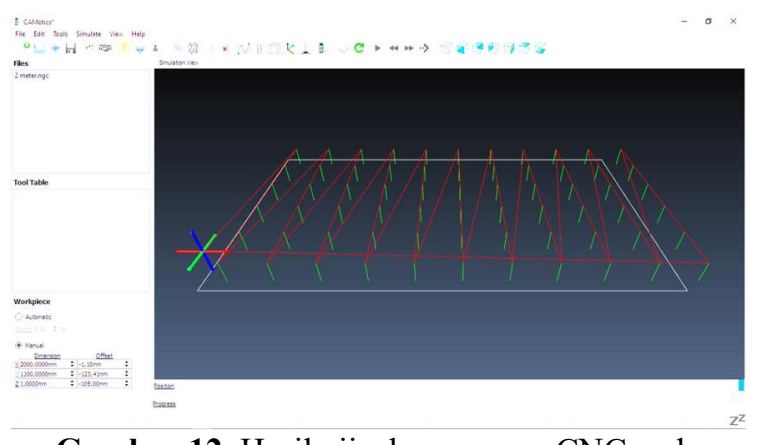

Gambar 12. Hasil ujicoba program $\mathrm{CNC}$ pada software CAMotics

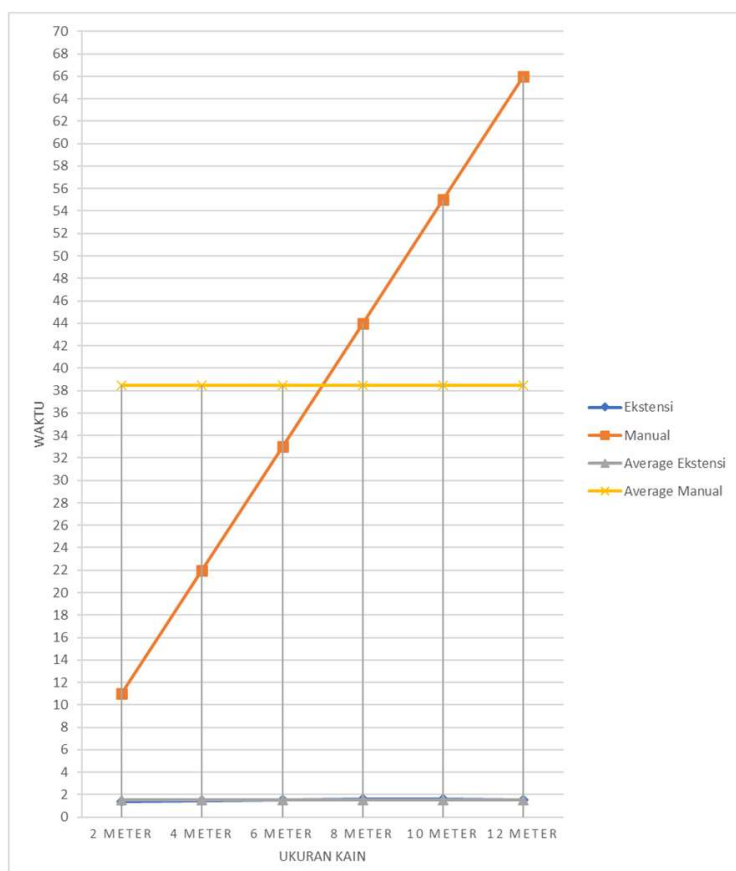

Gambar 13. Grafik waktu pembuatan program $C N C$

Hasil ujicoba yang dilakukan juga didapatkan beberapa data pembuatan program CNC. Data tersebut adalah data waktu pembuatan secara ketik manual dan pembuatan dengan menggunakan ekstensi yang dikembangkan. Data waktu yang telah diukur dapat dilihat pada Gambar 13.

Berdasarkan grafik pada Gambar 13, dapat dilihat bahwa waktu pembuatan program $C N C$ dengan menggunakan ekstensi yang dikembangkan pada software inkscape, memiliki waktu hampir sama untuk kain yang memiliki panjang yang berbeda. Hal tersebut karena pembuatan menggunakan ekstensi dikerjakan secara otomatis oleh komputer, sehingga didapatkan waktu yang relatif sama. Rata- rata waktu pembuatan program $C N C$ dengan menggunakan ekstensi tersebut adalah 1,52 menit. Proses tersebut dihitung mulai dari 
waktu penggambaran titik-titik pengecapan pada software inkscape dengan ekstensi "pengecapan batik" yang dikembangkan, dan waktu pembuatan program $C N C$ dengan ekstensi "Gcodetools".

Pembuatan program $C N C$ secara manual memiliki waktu yang berbeda dengan pembuatan menggunakan ekstensi. Berdasarkan grafik pada Gambar 4.13. waktu pembuatan program $C N C$ akan semakin lama untuk kain yang semakin panjang. Hal tersebut karena semakin panjang kain yang dikerjakan, akan membutuhkan baris program CNC yang semakin panjang juga, sehingga dibutuhkan tambahan waktu untuk pengetikan program CNC secara manual tersebut, untuk ukuran kain yang bertambah panjang. Rata-rata waktu pembuatan program CNC secara manual tersebut adalah 38,5 menit. Proses ini dihitung mulai dari bagian awal pengetikan baris program sampai akhir baris program sesuai dengan blok perintah pada mesin $C N C$.

Hasil perolehan waktu tersebut lalu dibandingkan antara proses dengan menggunakan ekstensi software inkscape dan secara manual. Berdasarkan perhitungan waktu didapatkan, pembuatan program $C N C$ dengan menggunakan ekstensi yang dikembangkan dalam penelitian ini memiliki waktu proses ratarata lebih cepat $96,06 \%$ apabila dibandingkan dengan pembuatan program $C N C$ secara manual. Hal tersebut karena pembuatan program CNC dengan ekstensi ini dilakukan otomatis oleh sistem kerja komputer.

\section{KESIMPULAN}

Berdasarkan hasil penelitian yang telah dilakukan pembuatan program $C N C$ untuk pengecapan batik dengan mesin $C N C$ dapat dibuat pada software inkscape, menggunakan ekstensi "Pengecapan Batik" yang telah dibangun dengan bahasa pemrograman Python. Penggunaan ekstensi tersebut dapat mengakomodir berbagai ukuran motif cap batik dengan ketentuan panjang $\mathrm{x}$ lebar, dan pada beberapa ukuran kain dengan panjang 2, 4, 6, 8, 10, dan 12 meter. Pembuatan program $C N C$ untuk pengecapan batik dengan ekstensi yang dikembangkan ini, dapat mengurangi waktu penyusunan sampai $96,05 \%$ apabila dibandingkan dengan penyusunan secara manual.

Terdapat beberapa aspek yang bisa dikembangkan berdasarkan hasil dari penelitian ini. Integrasi software hasil penelitian ini dengan produksi batik cap menggunakan mesin $C N C$ dapat dilakukan untuk mengetahui desain manufaktur yang sesuai untuk perancangan manufaktur batik cap. Software yang dikembangkan juga bisa dikaji lebih lanjut mengenai algoritma yang digunakan untuk membuat program $C N C$ untuk proses produksi batik tulis.

\section{DAFTAR PUSTAKA}

Alamsyah, A. (2018). Kerajinan Batik dan Pewarnaan Alami. Endogami: Jurnal Ilmiah Kajian Antropologi, 1(2), 136. https://doi.org/10.14710/endogami.1.2.13 6-148

Asmal, S., Subagyo, Wibisono, M. A., \& Sudiarso, A. (2015). Pengembangan Sistem CAD Motif Batik Berbasis Karakter. Seminar Nasional IENACO 2015, ISSN 2337-(2000), 218-225.

Dwinugroho, T. B. (2017). Implementasi Programmable Logic Control ( PLC ) pada Griper Mesin Batik Cap Otomatis Berbasis CNC. EJST (Industrial Engineering Journal of The University of Sarjanawiyata Tamansiswa), 1(1), 40-50.

Eskani, I. N., Haerudin, A., Setiawan, J., Lestari, D. W., \& Astuti, W. (2019). Batik Fungsional Sebagai Salah Satu Strategi Pengembangan Industri Batik Dalam Memasuki Era Industri 4.0. Prosiding Seminar Nasional Industri Kerajinan Dan Batik 2019, 1-12. https://proceeding.batik.go.id/index.php/S NBK/article/view/17/14

Hanif, M., Wibisono, M. A., \& Dharma, I. G. B. B. (2017). Perancangan Mesin Batik Cap Otomatis Tipe Modul Cap Bergerak. Prosiding Seminar Nasional Teknik Industri Universitas Gadjah Mada 2017, November, 87-94.

Issara Okvia Dita. (2017). Sistem Desain dan Manufaktur Pakaian Batik. Universitas Gadjah Mada.

Narendra Normasyah Fasla, A. B. W. (2013). Buku Visual Batik Jetisan Sidoarjo. Jurnal Desain Komunikasi Visual UPN "Veteran" Jatim, 2, 2010-2015.

Purba, E. J., Putra, A. K., \& Ardianto, B. (2020). Perlindungan Hukum Warisan Budaya Tak Beda Berdasarkan Convention for The Safeguarding Of The Intangible Cultural Heritage 2003 dan Penerapannya di 
Indonesia. Uti Possidetis: Journal of International Law, 1(1), 90-117.

Setyaningsih, I. (2020). TINGKAT KEPEDULIAN IKM BATIK TERHADAP ISU LINGKUNGAN : PERBANDINGAN DI YOGYAKARTA DAN PEKALONGAN The Level of Concern of IKM Batik to Environmental Issues: Comparison in Yogyakarta and
Pekalongan. Seminar Nasional Teknologi Industri Hijau 3, 90-95.

Wibisono, M. A., Dharma, I. G. B. B., Suwastono, A., \& Imani, M. A. (2012). Integrasi Desain dan Manufaktur Batik Cap. In Jurnal Imu Pengetahuan dan Teknologi Tepat Guna (Vol. 1, pp. 73-82). 